NASA/TM-2005-213666

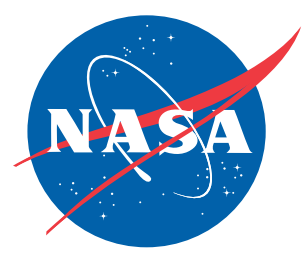

\title{
Development and Testing of Control Laws for the Active Aeroelastic Wing Program
}

Ryan P. Dibley, Michael J. Allen, and Robert Clarke NASA Dryden Flight Research Center

Edwards, California

Joseph Gera

Analytical Services \& Materials, Inc.

Edwards, California

John Hodgkinson

Spiral Technology, Inc.

Edwards, California 


\section{NASA STI Program ... in Profile}

Since its founding, NASA has been dedicated to the advancement of aeronautics and space science. The NASA scientific and technical information (STI) program plays a key part in helping NASA maintain this important role.

The NASA STI program is operated under the auspices of the Agency Chief Information Officer. It collects, organizes, provides for archiving, and disseminates NASA's STI. The NASA STI program provides access to the NASA Aeronautics and Space Database and its public interface, the NASA Technical Report Server, thus providing one of the largest collections of aeronautical and space science STI in the world. Results are published in both nonNASA channels and by NASA in the NASA STI Report Series, which includes the following report types:

- TECHNICAL PUBLICATION. Reports of completed research or a major significant phase of research that present the results of NASA programs and include extensive data or theoretical analysis. Includes compilations of significant scientific and technical data and information deemed to be of continuing reference value. NASA counterpart of peer-reviewed formal professional papers but has less stringent limitations on manuscript length and extent of graphic presentations.

- TECHNICAL MEMORANDUM. Scientific and technical findings that are preliminary or of specialized interest, e.g., quick release reports, working papers, and bibliographies that contain minimal annotation. Does not contain extensive analysis.
- CONTRACTOR REPORT. Scientific and technical findings by NASA-sponsored contractors and grantees.

- CONFERENCE PUBLICATION. Collected papers from scientific and technical conferences, symposia, seminars, or other meetings sponsored or co-sponsored by NASA.

- SPECIAL PUBLICATION. Scientific, technical, or historical information from NASA programs, projects, and missions, often concerned with subjects having substantial public interest.

- TECHNICAL TRANSLATION. Englishlanguage translations of foreign scientific and technical material pertinent to NASA's mission.

Specialized services also include creating custom thesauri, building customized databases, and organizing and publishing research results.

For more information about the NASA STI program, see the following:

- Access the NASA STI program home page at http://www.sti.nasa.gov.

- E-mail your question via the Internet to help@sti.nasa.gov.

- Fax your question to the NASA STI Help Desk at (301) 621-0134.

- Phone the NASA STI Help Desk at (301) 621-0390.

- Write to:

NASA STI Help Desk NASA Center for AeroSpace Information 7121 Standard Drive Hanover, MD 21076-1320 
NASA/TM-2005-213666

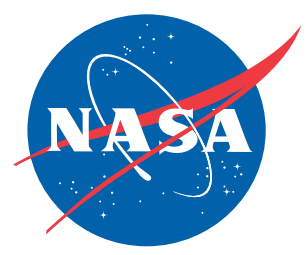

\section{Development and Testing of Control Laws for the Active Aeroelastic Wing Program}

Ryan P. Dibley, Michael J. Allen, and Robert Clarke NASA Dryden Flight Research Center

Edwards, California

Joseph Gera

Analytical Services \& Materials, Inc.

Edwards, California

John Hodgkinson

Spiral Technology, Inc.

Edwards, California

National Aeronautics and

Space Administration

Dryden Flight Research Center

Edwards, California 93523-0273

\section{December 2005}




\section{NOTICE}

Use of trade names or names of manufacturers in this document does not constitute an official endorsement of such products or manufacturers, either expressed or implied, by the National Aeronautics and Space Administration.

Available from the following:

NASA Center for AeroSpace Information

7121 Standard Drive

Hanover, MD 21076-1320

(301) 621-0390
National Technical Information Service 5285 Port Royal Road

Springfield, VA 22161-2171

(703) 605-6000 


\begin{abstract}
The Active Aeroelastic Wing research program was a joint program between the U.S. Air Force Research Laboratory and NASA established to investigate the characteristics of an aeroelastic wing and the technique of using wing twist for roll control. The flight test program employed the use of an F/A-18 aircraft modified by reducing the wing torsional stiffness and adding a custom research flight control system. The research flight control system was optimized to maximize roll rate using only wing surfaces to twist the wing while simultaneously maintaining design load limits, stability margins, and handling qualities. NASA Dryden Flight Research Center developed control laws using the software design tool called CONDUIT, which employs a multi-objective function optimization to tune selected control system design parameters. Modifications were made to the Active Aeroelastic Wing implementation in this new software design tool to incorporate the NASA Dryden Flight Research Center nonlinear F/A-18 simulation for time history analysis. This paper describes the design process, including how the control law requirements were incorporated into constraints for the optimization of this specific software design tool. Predicted performance is also compared to results from flight.
\end{abstract}

\title{
NOMENCLATURE
}

Ada high-level computer language developed for the U.S. Department of Defense

AAW Active Aeroelastic Wing

AFRL Air Force Research Laboratory

AIL aileron

ASE aeroservoelastic

CONDUIT $^{\circledR}$ Control Designer's Unified Interface

DFRC Dryden Flight Research Center

FDMS flight deflection measurement system

$g \quad$ acceleration of gravity

GM gain margin

ILEF inboard leading-edge flap

NASA National Aeronautics and Space Administration

OBES onboard excitation system

OLEF outboard leading-edge flap

$p_{\min } \quad$ roll rate at the first minimum of a step response

$p_{\text {peak }} \quad$ first overshoot of a step response

PIO pilot-induced oscillation

PM phase margin 


$\begin{array}{ll}\text { RFCS } & \text { research flight control system } \\ \text { RPO } & \text { rolling pullout } \\ \text { STAB } & \text { stabilator } \\ \text { TEF } & \text { trailing-edge flap } \\ \text { WUT } & \text { windup turn }\end{array}$

\section{OVERVIEW OF ACTIVE AEROELASTIC WING PROJECT}

The Active Aeroelastic Wing (AAW) research program was a joint program between the U.S. Air Force Research Laboratory (AFRL) and NASA established to investigate the use of a torsionally flexible wing for roll control through and beyond aeroelastic control reversal (ref. 1). This overview presents primary and secondary goals of the project, as well as the aircraft description and modifications. The following sections also provide details of the Phase I and Phase II flights.

\section{Goals}

The primary goal of the NASA Dryden Flight Research Center (DFRC, Edwards, California) controls effort was to create a design process and use this process to design a controller to maximize roll performance at 18 design points, using only wing control surfaces, while maintaining structural loads within design limits and maintaining adequate handling qualities. The secondary goal was to explore the use of leading-edge and trailing-edge control surfaces of a wing as aerodynamic tabs to twist the wing, creating rolling moments through wing twist rather than wing camber. In doing so, the amount of required surface deflection could potentially be reduced, allowing for hingeless designs that would reduce drag and improve the radar cross section signature of an aircraft. Furthermore, this control methodology requires a torsionally flexible wing, potentially reducing the amount of structure required in a wing and allowing for the use of higher aspect ratios.

\section{Aircraft Description and Modifications}

The aircraft selected for this program was an F/A-18A, shown in figure 1, modified by replacing the rear wing box skin panels to reduce the torsional stiffness of the wing. Additionally, the outboard leading-edge flap (OLEF) surfaces, which are normally driven in unison with the inboard leading-edge flaps (ILEFs), were provided with separate actuators to allow independent movement. Approximately 200 strain gages were added to the wing structure to measure wing loads. An extensive loads calibration was performed to derive the load equations to relate strain-gage measurements to structural loads (ref. 2). A flight deflection measurement system (FDMS) was installed to optically measure the positions of 16 targets on the left wing, thereby providing the capability of determining the bending and twisting of the wing during flight (ref. 3 ). Figure 2 shows the FDMS and target locations. 


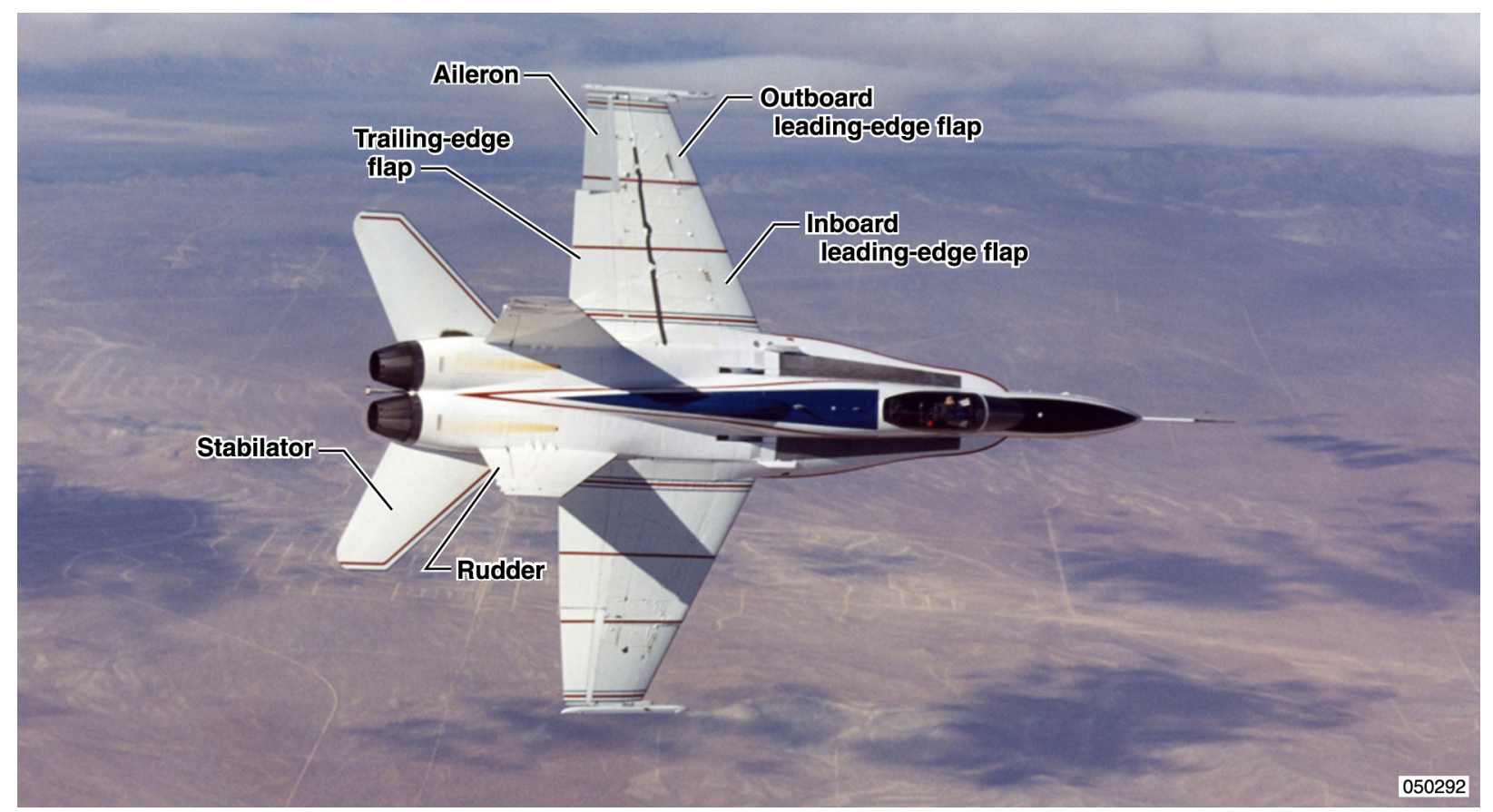

Figure 1. F/A-18 Active Aeroelastic Wing aircraft (control surfaces labeled).

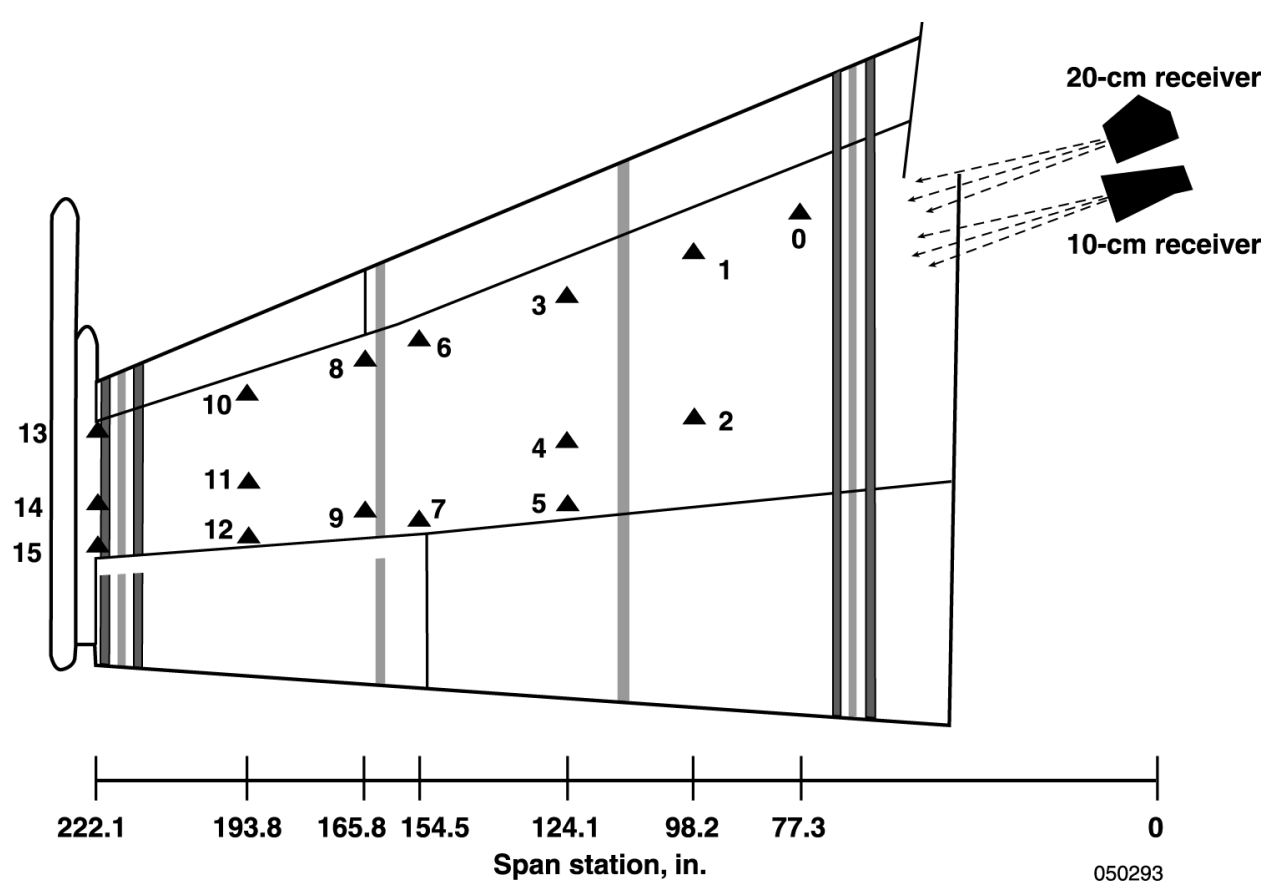

Figure 2. Flight deflection measurement system target locations (ref. 3). 
A research flight control system (RFCS) was interfaced with the F/A-18 flight computer such that custom control laws could be flown while still maintaining the ability to revert to the standard F/A-18 control laws at any time (ref. 1). Two flight phases were performed in the course of the AAW program. Phase I flights used an onboard excitation system (OBES) to add frequency sweep and doublet commands to the production F/A-18 control law surface commands (ref. 1), providing data for aerodynamic and structural loads model development. The RFCS was reprogrammed for the Phase II flights to incorporate the AAW control laws, controlling the aircraft independent of the production F/A-18 control laws.

\section{Phase I Flights}

Phase I of the AAW program was performed between November 2002 through June 2003 to gather flight data to create aerodynamic and structural loads models of the AAW aircraft for control law development. Fifty-one flights were flown using the RFCS with an OBES programmed to perform open-loop frequency sweeps and doublets. In addition to the OBES maneuvers, piloted maneuvers were flown using the baseline F/A-18 controller. The maneuvers included 5- $g$ windup turns (WUTs), $360^{\circ}$ rolls, and 4-g rolling pullouts (RPOs) (ref. 1). The data from these maneuvers were used to create delta values to the baseline aircraft stability derivatives (ref. 4). Additionally, the maneuvers were used to develop a linear structural loads model to predict wing and control surface structural loads based on aircraft states and control surface deflections. The structural loads model predicts wing-root bending and torsion, wing-fold bending and torsion, and wing surface hinge moments, for both wings (ref. 5). A third model was created to predict wing twist in a similar manner to the structural loads model; however, this model was not available in time for the control law development effort (ref. 3).

\section{Phase II Flights}

The 35 AAW Phase II flights began on December 14, 2004, to evaluate the newly developed AAW control laws. Maneuvers included stick raps, doublets, WUTs, bank-to-bank and $360^{\circ}$ rolls, and RPOs. Stick raps were used to check for flutter and aeroservoelastic (ASE) characteristics. Piloted doublets were performed to familiarize the pilot with the handling of the aircraft prior to more aggressive maneuvering. The 5-g WUTs were used to observe structural loading as a result of longitudinal maneuvering. These maneuvers provided a comparison to the production F/A-18 controller and gave expectations for how the structure would be loaded in the RPO maneuvers to follow. The $360^{\circ}$ rolls were executed to demonstrate roll performance and rolling using wing twist, while the 4- $g$ RPOs were used to demonstrate the same under loaded conditions.

\section{DESIGN TOOLS}

The design process for the AAW control laws required the integration of both pre-existing design tools as well as tools created specifically for the AAW project. The following sections give an overview and describe the integration of the primary design tool, CONDUIT, the AAW structural loads model, and the DFRC F/A-18 nonlinear simulation. 


\section{Overview of CONDUIT Design Tool}

The Control Designer's Unified Interface (CONDUIT ${ }^{\circledR}$, U.S. Army Aeroflightdynamics Directorate, Moffett Field, California) is a commercially available design tool that employs a multi-objective function optimization to tune selected control system design parameters (ref. 6). The software operates within the MATLAB $^{\circledR}$ (The MathWorks, Natick, Massachusetts) environment. Aircraft dynamics and the control system block diagrams are modeled in Simulink. Design parameters, to be optimized by CONDUIT, can be specified as any parameter of any Simulink block, but typically are defined as gains. The constraints and objective function of the optimization are defined using a number of specifications, which are analogous to two-dimensional handling qualities specification plots. Figure 3 illustrates an example of a CONDUIT specification.

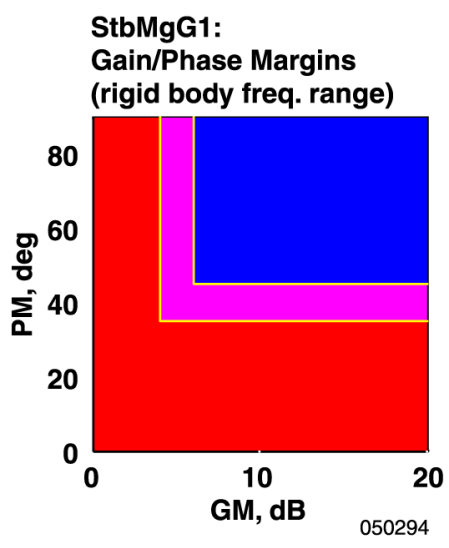

Figure 3. CONDUIT specification (blue - level 1; magenta - level 2; red - level 3).

The CONDUIT specifications can be used to represent actual handling qualities specifications, or as general constraints or objectives of the optimization. Each specification contains level 1, level 2, and level 3 regions, corresponding to blue, magenta, and red regions, respectively. Regarding handling qualities specifications, these levels correspond directly to the Cooper-Harper scale levels (ref. 7). Concerning all other specifications, the levels are merely used for evaluation. All specifications are evaluated graphically by CONDUIT.

A typical CONDUIT problem will contain specifications for basic stability, handling qualities requirements, and performance objectives. The AAW program used all of these categories and added a fourth category consisting of structural loads. The specifications are given constraint priorities, allowing the user to fine tune the optimization process. Listed in order of decreasing priority, they are: hard, soft, objective, summed objective, and check only. The system is optimized in three phases by first satisfying the hard constraints, then satisfying the soft constraints, and finally optimizing the objective and summed objective specifications. Check-only specifications are not involved in the optimization but are available to the designer to gain insight about the system. 


\section{Active Aeroelastic Wing Structural Loads Model}

A program requirement placed on the AAW control law design was that structural loads had to be maintained within their design limits. This requirement initiated the development of a predictive structural loads model for use in the control law design. Flight data from Phase I flights were used to create a loads model based on 15 aircraft state and surface deflection inputs. The model predicted the following loads for the left and right wing: wing-root bending, wing-root torsion, wing-fold bending, wing-fold torsion, ILEF hinge moment, OLEF hinge moment, trailing-edge flap (TEF) hinge moment, and aileron (AIL) hinge moment. Model coefficients defined unique models at each of the 18 design points (ref. 5).

In order to incorporate the structural loads model into the design process, six CONDUIT specifications were created to constrain loads during the optimization. Figure 4 shows these specifications. A wing-root bending-torque specification and a wing-fold bending-torque specification constrained these loads for the left and right wing to remain within a defined envelope. Four hinge-moment specifications constrained each of the wing surfaces on the left and right wing. For each of these specifications, the borders between the level 2 region (magenta) and level 3 region (red) represented the 100-percent load limit, while the borders of the level 1 region (blue) were based on the predicted load limit uncertainty of the structural loads model for the specific load prediction. Thus, designing to these more restrictive borders (although potentially sacrificing performance) ensured the greatest probability of maintaining structural design limits in flight.
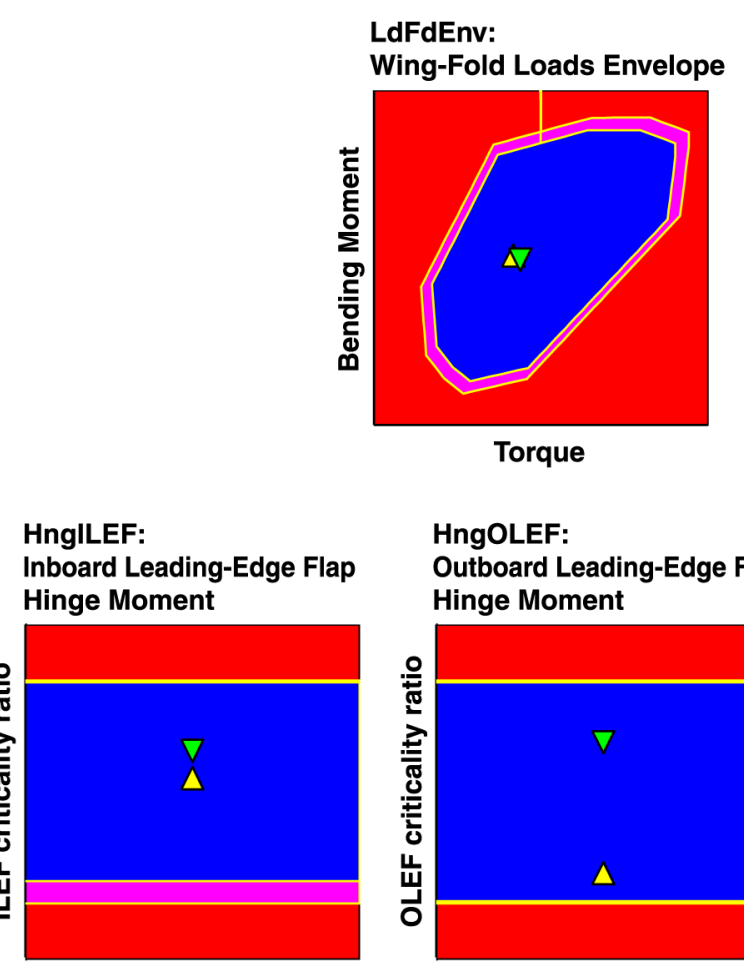

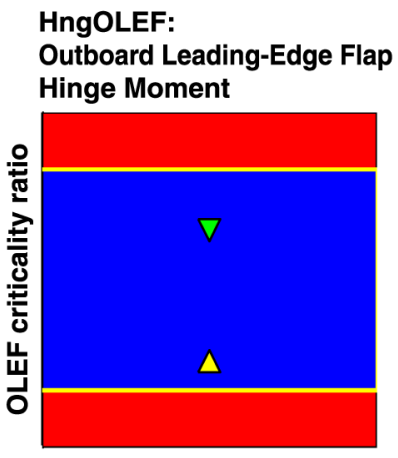

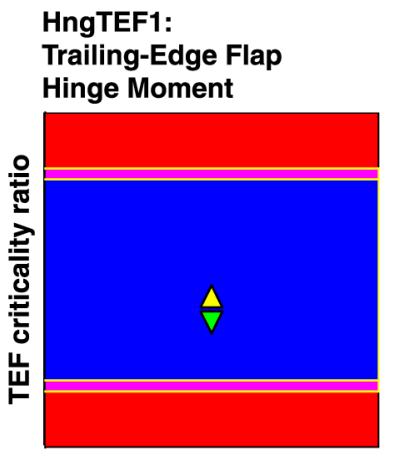

HngAil1:

Aileron Hinge Moment

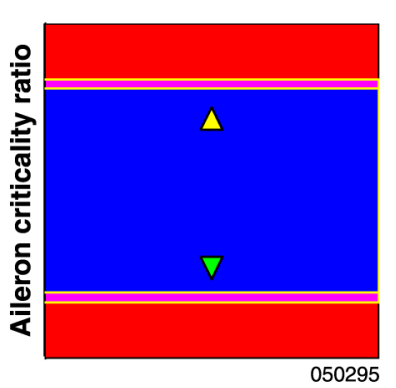

Figure 4. Load specifications. 


\section{Implementation of DFRC F/A-18 Nonlinear Simulation into CONDUIT}

A typical application of CONDUIT contains a nonlinear Simulink model, incorporating linearized aerodynamics in a state space form. The implementation of AAW in CONDUIT initially used this approach. Later, the decision was made to replace the Simulink model with a higher fidelity simulation, namely the DFRC nonlinear six-degree-of-freedom AAW F/A-18 simulation.

The method by which CONDUIT evaluates the system lent itself to such a modification. CONDUIT specifications are self-contained modules of code which, based on their type, either linearize the system for frequency-based analysis or run time history simulations for time-based analysis. The results are analyzed by each specification, which subsequently displays the results graphically. Modifying the specifications to use the nonlinear simulation was simply a matter of bypassing the normal routines of calling Simulink, replacing them with calls to run the nonlinear simulation. Data from the nonlinear simulation were next formatted to match the expected output from Simulink, and the specifications would then continue to run as if nothing had changed. Frequency-based specifications of the AAW CONDUIT problem used the standard method of evaluation, using a linear Simulink model.

Several benefits could be gained by using the DFRC nonlinear AAW F/A-18 simulation. First, the full nonlinear aircraft dynamics could be used. Additionally, the RFCS Ada control laws, used in flight, could be used directly, avoiding the problem of creating an identical Simulink representation. Finally, because of the complexity of the AAW control laws, the nonlinear simulation with the AAW control laws would run faster than real time and approximately two to three times faster than the Simulink simulation.

There were two negative aspects to using the nonlinear simulation within CONDUIT, both related to the algorithm used to trim the aircraft. Each reset of the nonlinear simulation to the nominal conditions required approximately 30 seconds to trim the aircraft. Thus, the time gained by the increased run speed was negated by the increased time required to trim the simulation before each run. The second problem would occur infrequently. While still untrimmed, the simulation would reach a dynamic state that passed the trim criterion. The simulation would run prematurely, returning spurious results that could send the optimization in the wrong direction. It was discovered, however, that these instances were small enough in number that CONDUIT could recover from them. Overall, the benefits of using the nonlinear simulation outweighed the problems it introduced.

\section{CONTROLLER DESIGN}

This section discusses the details of the AAW control law design process. Subsections include descriptions of the longitudinal, lateral, and directional control law architectures, the selection of design parameters, the design regions and strategies, and the design process. 


\section{Control Law Architecture}

The AAW control law structure was based on the production F/A-18 controller. Components of the system not active in the AAW flight envelope were removed to simplify the system. In addition, modifications were made to enable specific AAW control strategy requirements. The AFRL contractor defined these strategies, requirements, and the resulting architecture. The NASA DFRC designs discussed in this paper were required to fit within this fixed architecture.

\section{Longitudinal Controller}

Figure 5 illustrates a simplified representation of the AAW longitudinal control system, showing only the basic structure and AAW specific components. Although the basic feedback structure remained the same as the production F/A-18 controller, the AAW controller differed in that, rather than sending the pilot command error signal to only the stabilator (STAB), the controller branched this signal to all of the wing surfaces as well. Each of the five branches (ILEF, OLEF, TEF, aileron, and stabilator) had a gain and bias value, allowing the user to define the mixing of the surfaces and their trim values.

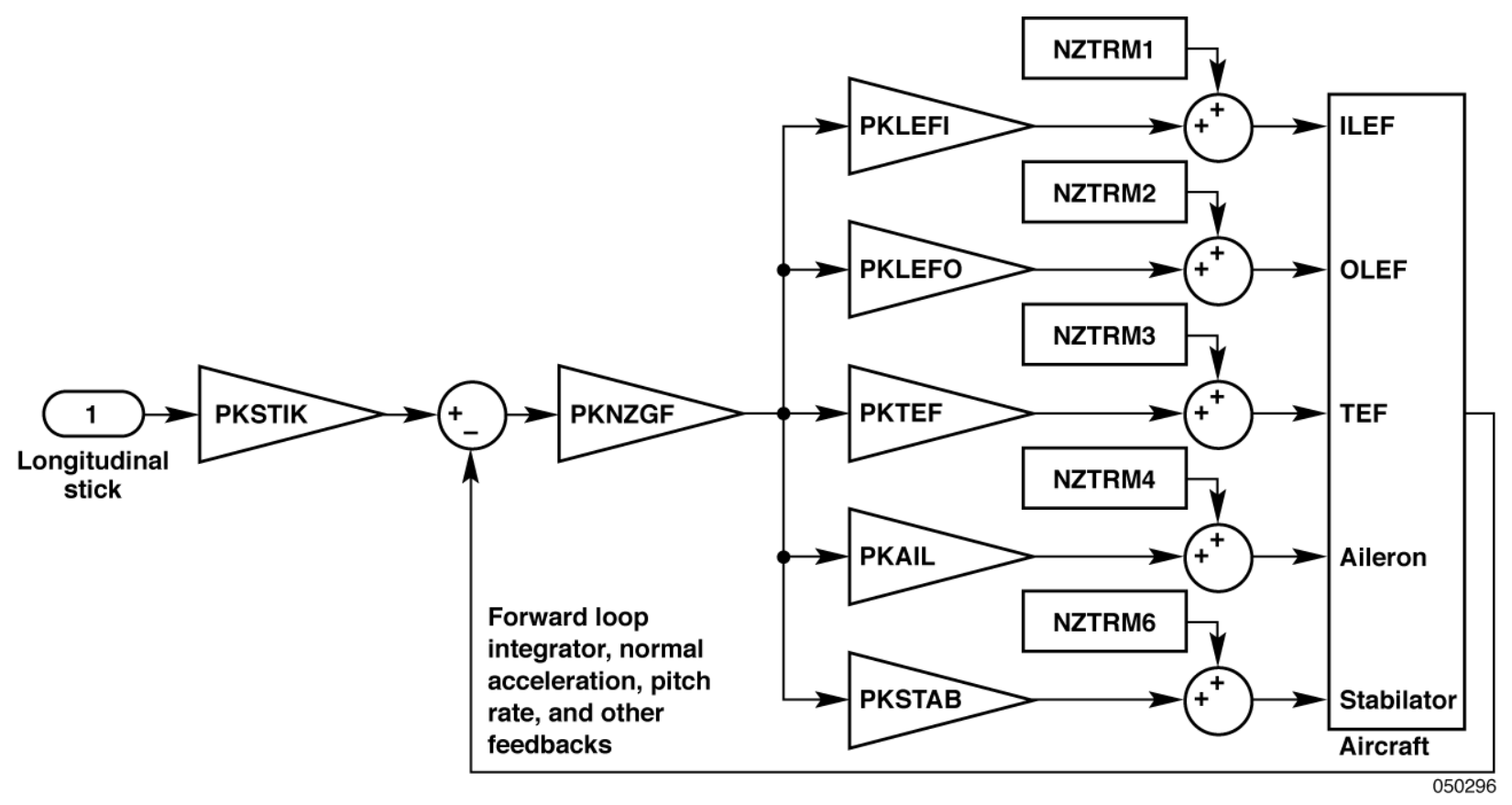

Figure 5. Simplified longitudinal control laws.

\section{Lateral Controller}

Figure 6 shows the AAW lateral-axis controller, simplified to illustrate only the basic structure and AAW specific components. As with the longitudinal controller, the architecture was very similar to the production F/A-18 control laws but with elements removed that were not required within the planned AAW flight conditions. Similar to the longitudinal controller, the pilot command 8

error was branched into four signals, each with a gain, for the four wing control surface differential 
commands. Additionally, roll-rate feedback was split directly into four signals, each with a gain, for a second set of wing control surface differential commands. The four roll-rate feedbacks are summed with the four pilot command error signals, resulting in the four wing surface differential commands. The differential stabilator was commanded to zero so that wing-only roll control could be studied.

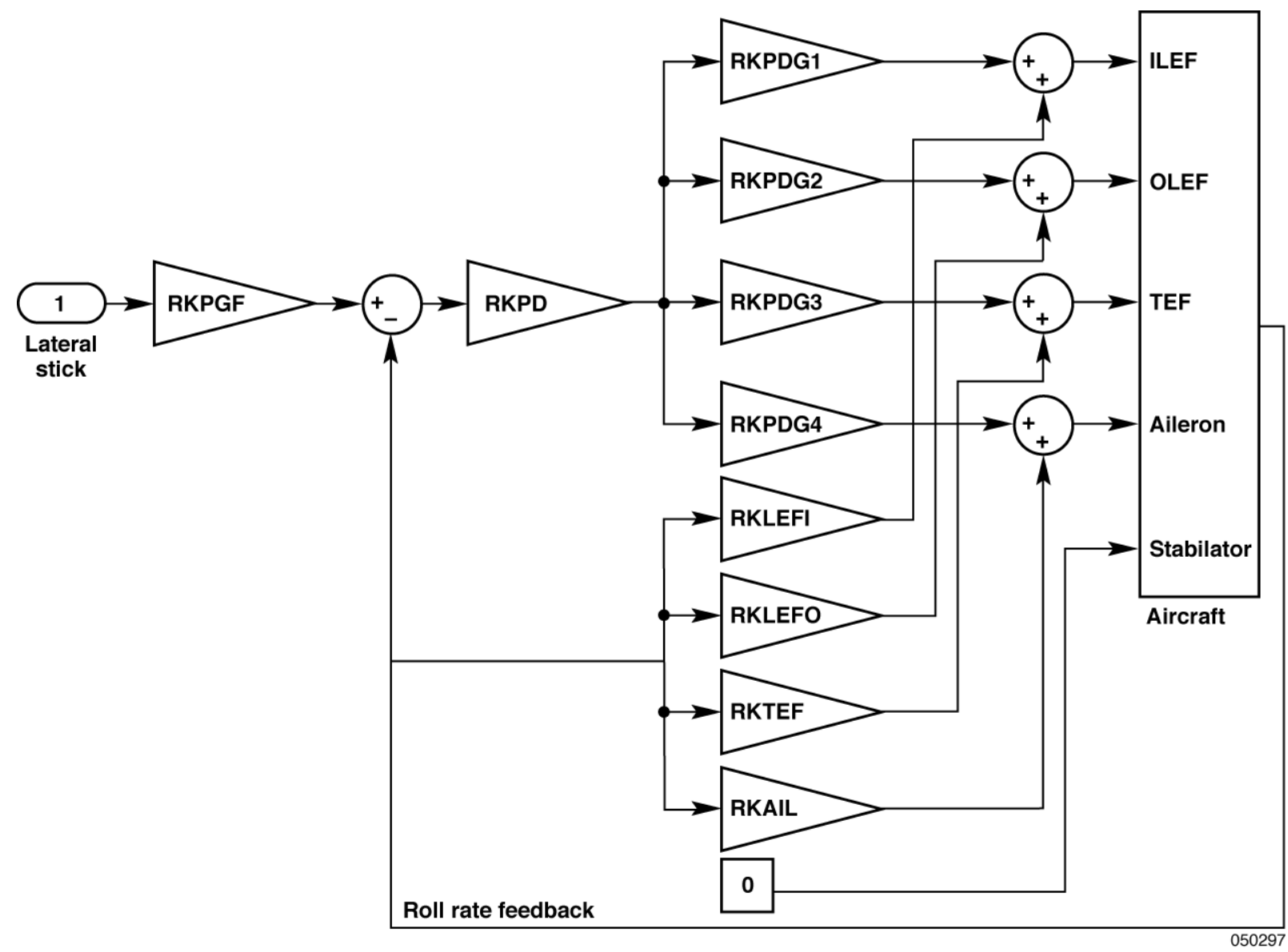

Figure 6. Simplified lateral control laws.

\section{Directional Controller}

Of the three axes, the directional controller was the least modified. Simplifications were made as with the other two axes, and a single gain was added to the rolling surface rudder interconnect signal. This gain was seldom used; and for the purpose of this paper, the directional controller can be assumed to be the same as in the production F/A-18 control laws.

\section{Design Parameters}

Table 1 lists the 23 design parameters that were available for the optimization. In order to simplify the design effort, the gains were held constant at each design point rather than being scheduled. 
Table 1. Design parameter names and descriptions.

\begin{tabular}{ll}
\hline \hline \multicolumn{2}{c}{ Longitudinal Gains and Trim Biases } \\
\hline PKSTIK & Pilot longitudinal stick gain \\
PKNZGF & Pitch loop gain \\
PKLEFI & ILEF gain \\
PKLEFO & OLEF gain \\
PKTEF & TEF gain \\
PKAIL & AIL gain \\
PKSTAB & STAB gain \\
NZTRM1 & ILEF trim bias \\
NZTRM2 & OLEF trim bias \\
NZTRM3 & TEF trim bias \\
NZTRM4 & AIL trim bias \\
NZTRM6 & STAB trim bias \\
\hline & Lateral Gains \\
\hline RKPGF & Pilot lateral stick gain \\
RKPD & Pilot roll-command error loop gain \\
RKLEFI & ILEF roll-rate gain \\
RKLEFO & OLEF roll-rate gain \\
RKTEF & TEF roll-rate gain \\
RKAIL & AIL roll-rate gain \\
RKPDG1 & ILEF pilot roll-command error gain \\
RKPDG2 & OLEF pilot roll-command error gain \\
RKPDG3 & TEF pilot roll-command error gain \\
RKPDG4 & AIL pilot roll-command error gain \\
\hline & Directional Gain \\
\hline YKRUD & Roll-rate crossfeed gain \\
\hline
\end{tabular}

\section{Design Regions and Corresponding Strategies}

The AAW technology relies on the flexibility of the wing, as well as the ability of the wing control surfaces, to effectively twist the wing. In order to twist the wing, the dynamic pressure on the control surfaces must be above a critical value. The critical dynamic pressure defines a region where control transitions from conventional control to wing twist control. An AAW aircraft would likely have to be able to transition from conventional control to wing twist control as the aircraft moves through this critical dynamic pressure region. This process of transitioning from conventional to wing twist control occurs gradually. Figure 7 shows the effectiveness of the wing control surfaces over a range of dynamic pressures for a general AAW aircraft, but does not specifically represent the F/A-18 used in the AAW program. Four design regions were defined to establish control strategies across the range of dynamic pressures. 


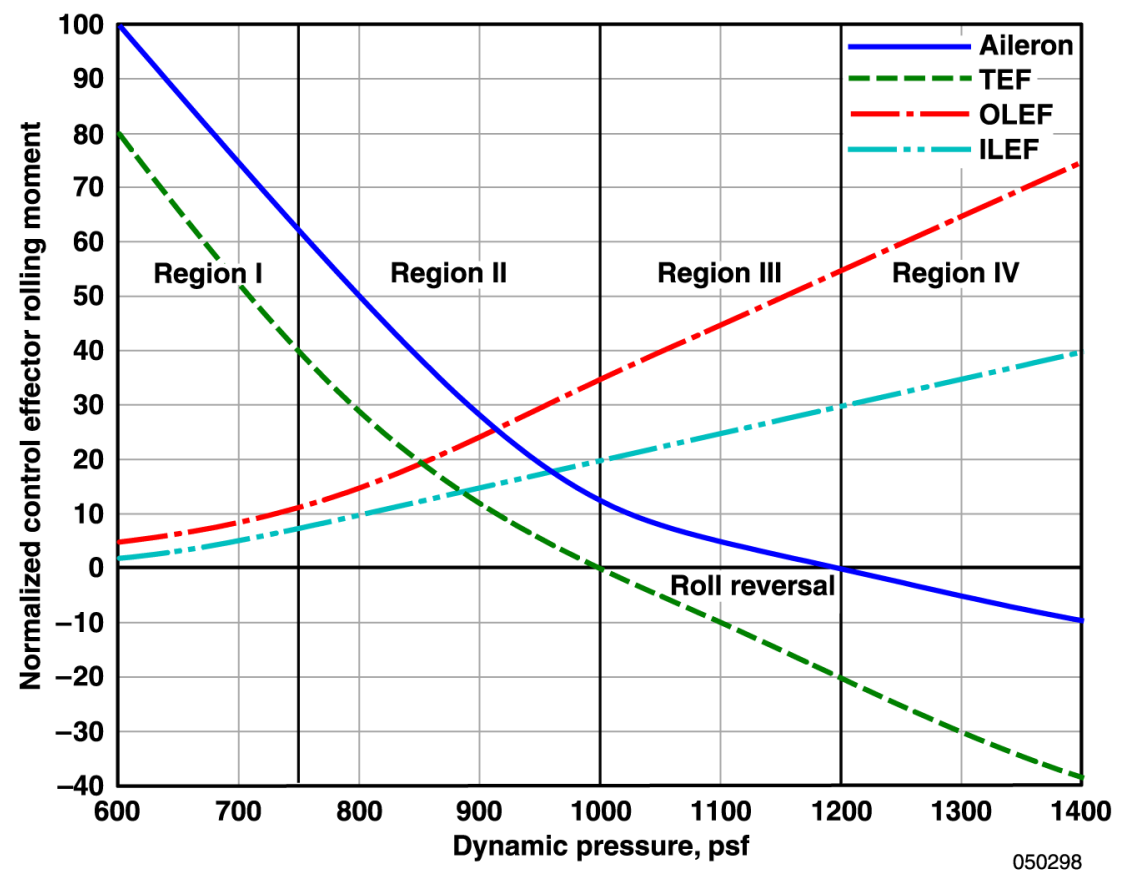

Figure 7. Wing flexibility design regions.

\section{Region I}

Region I defines a conventional wing. Dynamic pressure is too low to produce significant twist on the wing. As a result, the leading-edge control surfaces produce very little rolling moment. Twist produced by trailing-edge control surface deflection, which normally opposes the lift as a result of wing camber, is insignificant. The ideal strategy in this region is to favor the use of trailing-edge surfaces, rolling the aircraft primarily using lift derived from wing camber.

\section{Region II}

At the higher dynamic pressures of region II, the leading-edge surfaces can twist the wing a small amount. The trailing-edge surfaces are still capable of producing rolling moments by means of wing camber; however, they impart a twisting on the wing that reduces their overall effectiveness. A wing in region II benefits the most by deflecting the control surface positions to an optimal combination that maximizes rolling moment using a combination of camber and twist.

\section{Region III}

In region III, the leading-edge control surfaces are capable of generating large amounts of wing twist, which produces significant rolling moments. The trailing-edge surfaces are at or near the point of control reversal, where the opposing wing twist and wing camber effects are balanced. In this region, two control strategies could be taken. The first strategy uses the leading-edge surfaces to twist the wing, creating rolling moments. Alternately, conventional use of the trailing-edge surfaces could be extended into this region by using the leading-edge surfaces to counter the adverse twist created by the trailing-edge surfaces. 


\section{Region IV}

Both the leading-edge and trailing-edge control surfaces are capable of significant twist in region IV. Thus, only wing twist is used to create rolling moments. Leading-edge surfaces are used to twist the wing with greater effectiveness than in the other regions. Trailing-edge surfaces are used in control reversal, also creating rolling moments using wing twist.

\section{Predictions and Reality}

Early predictions of the performance of the AAW wing showed that control surface reversal would occur somewhere within the planned AAW flight test envelope, suggesting the possibility of seeing all four design regions. Unfortunately, the increase in wing flexibility was much smaller than expected, resulting in observed behavior only in regions I, II, and III (ref. 2). Although not a complete picture, these three regions can still demonstrate the AAW concept up to the reversal point.

\section{Longitudinal Design}

The design of the longitudinal system was not the primary goal of the AAW project. Despite the fact that the system was designed to provide active load alleviation, the DFRC design team decided that this concept had been explored in a previous research project and did not contribute directly to the wing twist methodology (ref. 8). Thus, the DFRC requirements on the longitudinal control system were that this system had to satisfy structural load limits as well as basic handling and stability criteria. These criteria included gain margin (GM) and phase margin (PM), short period damping ratio, short period frequency and acceleration sensitivity, stick force per $g$, equivalent time delay, and pilot-induced oscillations (PIOs). In order to focus the design effort on the lateral controller, the DFRC team chose to design the AAW controller to mimic the F/A-18 longitudinal controller, which already satisfied these requirements. CONDUIT was used only to verify that the longitudinal control law requirements were met.

\section{Lateral Design}

The goal of the lateral control system design was to create a controller that would roll the aircraft according to the four design regions to maximize roll rate, while simultaneously maintaining structural loads within their design limits and adhering to handling qualities requirements. The ten gains listed in Table 1 were defined for the lateral control laws. The pilot stick gain was set with RKPGF, while the inner loop roll-rate error gain was set with RKPD. The remaining eight gains were assigned to each of the four wing surfaces, two per surface.

The first set of four gains was applied to the roll-rate feedback signal, one for each of the wing control surfaces. These gains could be used individually to shape the response of a particular control surface or collectively to change the effective roll damping of the aircraft. The natural roll damping of the aircraft was seen to be sufficient and did not require modification. Shaping of the control surface response was also not necessarily required, but was an available option 
to smooth out transient hinge-moment loads. Thus, the approach to the lateral design was to optimize the system without these four gains, applying nonzero values to them only if transient hinge-moment loads were observed. Throughout the process of designing the control laws, however, these four gains were never required.

The other set of four gains was applied to the pilot roll-rate command error signal, split to each of the four wing control surfaces. These gains were given to CONDUIT as design parameters for the lateral control system optimization, and control the mixing and magnitude of the wing control surface positions as a result of roll commands.

The AAW lateral design was largely a problem of determining a mixing function for the four wing surfaces for rolling maneuvers. Afterwards, the inner loop gain (RKPD) and pilot stick gain (RKPGF) were adjusted to disable the feedback loop, since additional disturbance rejection was not required.

\section{Specifications and Constraints}

Table 2 shows a list of the AAW specifications, grouped by constraint type, in order of relative importance to the optimization. The first phase of a CONDUIT optimization starts with the hard constraints, where CONDUIT will make any changes necessary to move these specifications into level 1, even if that means violating the other constraint groups. Once this has been accomplished, CONDUIT moves the optimization into the second phase, in which the soft and summed objective specifications are moved into level 1 while maintaining the level 1 rating of the hard constraints. At this point, the third optimization phase begins. In this third phase, the optimization works to move the individual objective and summed objective specifications as far into level 1 as possible, again without violating the hard or soft constraints. Additionally, the optimization works to achieve the same result for the sum of the summed objective specifications. This summation constrains the possible see-saw effect, in which one objective specification is improved at the expense of another, and vice versa. Check-only specifications are only for reference and are not included in the optimization. They are included in a design to provide further insight about the optimization to the designer. They also provide a convenient way of temporarily removing a specification from the optimization without having to delete the specification permanently.

The hard constraints of the AAW problem were reserved primarily for stability. Since the results of many of the specifications are invalid for an unstable aircraft, designating only stability specifications as hard constraints ensures that the optimization will ignore any of these invalid results until stability is achieved. At that point, the optimization will evaluate the remaining specifications, which would then be returning valid results. The EigLcG1 specification ensures that all poles are stable, while the StbMgG1 specification maintains gain and phase margins of $6 \mathrm{~dB}$ and $45^{\circ}$ respectively. This specification was set to evaluate all three axes. The RFCSEng specification monitors the status of the RFCS engage status to prevent undesired disengagements from RFCS during maneuvering. 
Table 2. Active Aeroelastic Wing lateral design CONDUIT specifications.

\begin{tabular}{lcl}
\hline \hline \multicolumn{1}{c}{ Specification } & Constraint & \multicolumn{1}{c}{ Description } \\
\hline EigLcG1 & Hard & Eigenvalues \\
StbMgG1 & Hard & GM/PM \\
RFCSEng & Hard & RFCS engage enforcement \\
LdFdEnv & Soft & Wing-fold loads envelope \\
LdRtEnv & Soft & Wing-root loads envelope \\
HngILEF & Soft & ILEF hinge moment \\
HngOLEF & Soft & OLEF hinge moment \\
HngTEF1 & Soft & TEF hinge moment \\
HngAil1 & Soft & AIL hinge moment \\
MinBta1 & Soft & Sideslip excursions during roll \\
RollOsc & Soft & Roll-rate oscillations \\
LatAcc1 & Soft & Lateral acceleration at pilot station \\
MinBta2 & Soft & Constraining of beta excursions \\
MaxRoR1 & Summed objective & Maximization of roll-rate \\
PrfRoD1 & Summed objective & Time to bank \\
SMinAil & Check-only & Visualization of AIL deflection only \\
SMinILF & Check-only & Visualization of ILEF deflection only \\
SMinOLF & Check-only & Visualization of OLEF deflection only \\
SMinTEF & Check-only & Visualization of TEF deflection only \\
RollTC1 & Check-only & Roll mode time constant \\
RollED1 & Check-only & Roll equivalent delay \\
MinBeta & Check-only & Visualization of sideslip only \\
LdBtaQb & Check-only & Vertical tail load constraint \\
LatPIO1 & Check-only & Lateral-directional PIO \\
RollTC2 & Check-only & Roll mode time constant on centering stick \\
RollED2 & Check-only & Roll equivalent delay on centering stick \\
\hline \hline & & \\
\end{tabular}

The soft constraints comprised the largest number of specifications. The first six specifications constrain loads to remain within limits during maneuvering. These include the wing-root and wing-fold loads, and the four wing surface hinge moments. Each of these specifications contained evaluations for both the left and right wings and surfaces. The MinBtal specification constrained sideslip due to rolling maneuvers to within the MIL-F-8785C (ref. 9) level 1 boundaries of $2^{\circ}$ proverse and $6^{\circ}$ adverse yaw. RollOsc enforced the requirement that the roll rate at the first minimum $\left(p_{\text {min }}\right)$ following the first peak $\left(p_{\text {peak }}\right)$ should be at least 60 percent of the initial peak, illustrated in figure 8 . This requirement was restricted even further to 90 percent, being both more 14 desirable and attainable. 


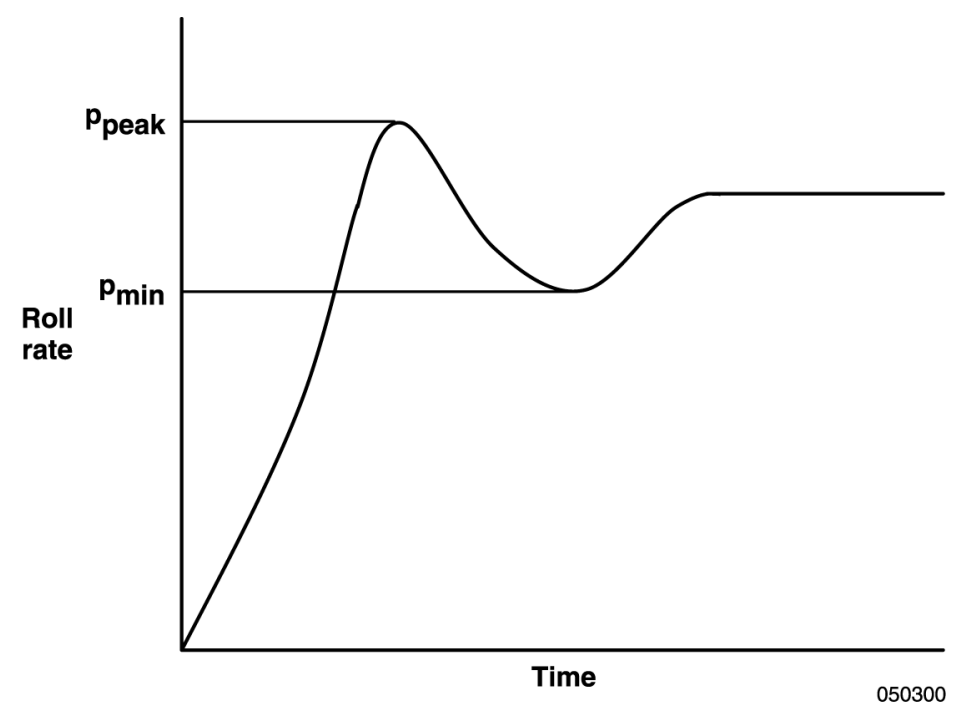

Figure 8. Roll oscillations after first peak.

LatAcc1 evaluated the lateral acceleration at the pilot's head, as defined by MIL-STD-1797 (ref. 10). This guideline was developed for a class III aircraft with very low roll rates. It was found that the guideline did not scale well to the roll rates of the AAW aircraft. Discussions with the aircraft manufacturer resulted in an acceptable level 2 value of less than $\pm 0.75 \mathrm{~g}$. MinBta2 was included to ensure sideslip remained within the MinBtal sideslip limits for a full stick, 1 -second pulse.

There were two summed objective specifications that form the focus of the optimization. The first, MaxRoR1, determines the steady-state roll rate due to a step input, plotting it onto a one-dimensional specification, shown in figure 9. This type of specification has only one active axis ( $y$-axis), while the other axis is held at a constant value, centered in the plot. This type of specification is useful for evaluating a single parameter. As a summed objective specification, the optimization will attempt to push the evaluated point as far into level 1 as possible, maximizing roll rate. The second summed objective specification, PrfRoD1, calculates the time to bank to $90^{\circ}$, plotting the value on a one-dimensional specification. Again, the optimization routine will try to move this value into level 1 as far as possible, minimizing the time to bank.
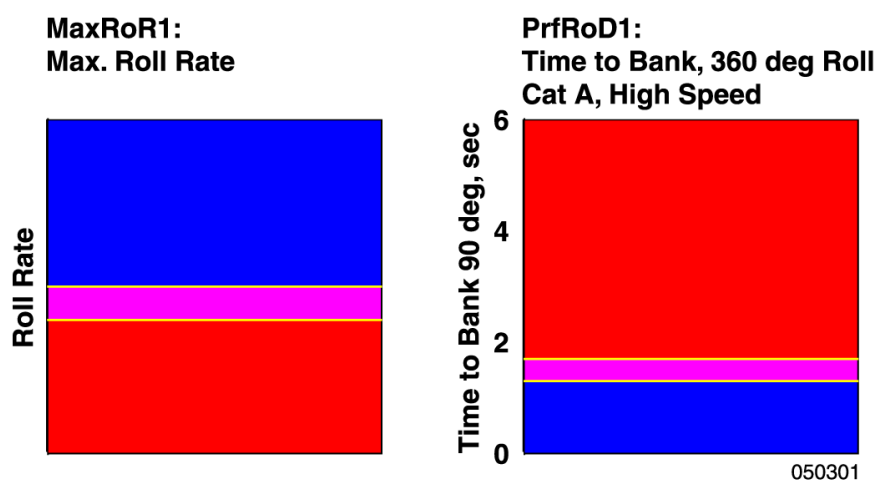

Figure 9. One-dimensional CONDUIT specifications, MaxRoR1 and PrfRoD1. 
In addition to optimizing the individual summed objectives, the optimization would also try to minimize the sum of the two summed objectives. Since the MaxRoR1 and PrfRoD1 specifications were mutually beneficial, this part of the optimization task was simplified.

There were many check-only specifications in the AAW CONDUIT problem, included primarily to provide further information about the system during the design process. These included specifications to visualize the wing control surface deflections and aircraft sideslip. Additionally, a number of soft constraints were converted to check-only specifications to simplify the optimization cost function. Some of these were converted because they did not drive the optimization, but were easily satisfied by achieving level 1 ratings in a few critical specifications. The remaining specifications were converted to check only because their algorithms were unreliable or inconsistent and caused problems with the optimization. After completion of the optimization, the specifications that had been converted from soft constraints were checked for violations.

\section{Modifications to Optimization Process}

Modifications were made to the AAW implementation in CONDUIT to improve the efficiency and accuracy of the optimization. The implementation of the AAW constraints in CONDUIT required 30 time history simulations for a complete evaluation, but only 2 of these were unique. Rather than running all 30 simulations, the specifications were modified so that only the 2 unique simulations were run; and the remaining specifications were modified to reuse the data. This modification reduced the required run time by a factor of 15 . Since a typical CONDUIT problem might require several hundred evaluations for a complete optimization, the time savings of this modification was significant. The accuracy was improved through the incorporation of the DFRC nonlinear AAW F/A-18 simulation, as described earlier in this paper, resulting in time histories created with the most accurate models available. Both of these modifications are not typical, require detailed knowledge of CONDUIT, and demonstrate possible improvements for future versions of this design tool.

\section{Optimization}

A typical optimization would start with the four roll-rate command error gains set to 1.0 , the four roll-rate feedback gains set to zero, RKPD set to 1.0, and RKPGF set to a value based on flight condition. All gains except the four wing surfaces gains would be frozen, that is, removed from the active set of design parameters. The optimization usually reached Phase II immediately or after a few evaluations of the system. If after several iterations, the roll rate or time-to-bank specifications could not be moved into level 1, the borders of these specifications were adjusted to allow the optimization to move to Phase III. CONDUIT would then work to improve the roll rate and time to bank as much as possible.

Specifically, test points within design regions I and II were optimized using the previous procedure on all four wing surface gains. This optimization allowed the largest roll rates within the conventional and transitional regions, a design approach that would be typical for an AAW aircraft in these regions. 
For test points that fall within design regions III and IV, where wing twist becomes effective, an alternate approach was taken. The trailing-edge surface positions were zeroed and frozen at the start of the optimization to allow CONDUIT to maximize roll rate using only the leading-edge surfaces and, in turn, wing twist. After the optimization was allowed to progress as much as possible, the use of the trailing-edge surfaces was explored. Since region IV was not achieved and few test conditions met the criteria for region III, this approach was applied to some of the region II test points as well. This artificially restricted the trailing-edge surfaces to create additional "region III-like" designs that used primarily wing twist to roll the aircraft.

Typically, the optimization would end with either the sideslip or wing control surface hinge moments at their limits. Since an optimization of this complexity will often have multiple local minimums, the designer would then investigate the history of the optimization, supporting information about the current system, and sensitivity analysis of the active design parameters to determine if further improvement were possible. From this, the number of active design parameters could be changed to refine the optimization at the current minimum. Alternately, the design parameter values could be changed manually to provide a new direction to the optimization or to break out of a local minimum. The degree of user intervention required varied at each flight condition from zero intervention to several redirections of the optimization.

\section{PHASE II FLIGHT DATA}

Figure 10 through figure 14 show results from left and right $360^{\circ}$ rolls at a region III design point. Left and right full-stick rolls are shown in each plot along with the predicted response from a right full-stick roll from the AAW F/A-18 simulation. Although the aircraft loads and handling qualities requirements are not shown in the following plots, these requirements remained within limits for both predicted and actual maneuvering. All of the plots within this section share common time scales.

Figure 10 shows the roll rates from the predicted simulation and the two $360^{\circ}$ rolls from flight. The predicted and flight right rolls show similar roll rates, with the flight results being slightly higher than that of the simulation. The roll rate for a left roll was slightly higher than for the right roll; a trend consistent with Phase I results and most likely caused by asymmetry in the aircraft (ref. 1). Figure 11 shows that sideslip remains within the level 1 region for proverse sideslip for the duration of each roll. Predicted sideslip matched the flight data closely throughout the roll. Differences between the predicted and flight responses at the end of the roll were a result of differences in the stick commands.

Figure 12 shows surface deflections for the full-stick rolls. The rudder plot shows the average collective rudder deflection, while the remaining plots show surface differential deflections; representing the included angle between the left and right surfaces. From these plots, it is apparent that the only wing surfaces that moved appreciably were the OLEFs. The rudders moved to counter the sideslip, and the stabilator differential command was essentially zero. Differences between the surface deflections from flight and those from the simulation were due to inaccuracies in the aerodynamic hinge-moment predictions in the AAW F/A-18 nonlinear simulation. At this particular flight condition, the aileron was at the reversal point, making this a region III test point. 
The OLEFs were found to be the most effective surface; more effective than any combination of the other surfaces. Additionally, other surface combinations with OLEF were found to violate hinge-moment or sideslip limits.

As stated earlier in this paper, figure 2 shows the locations of the FDMS targets. For the two rolling maneuvers discussed in this section, however, only targets 10, 12, 13, and 15 were active; providing twist at spanwise locations $193.8 \mathrm{in.}$ and $222.1 \mathrm{in}$. Figure 13 and figure 14 show the left wing twist at the two outboard twist stations for a right and a left roll, respectively. The dark blue (solid line) segments indicate valid data whereas the light blue (dashed line) segments indicate a span of time in which the optical sensor data was invalid. The right roll shows an increase in twist (leading edge up) of the left wing, the correct direction for creating a roll through wing twist. Likewise, the left roll shows a decrease in wing twist, also in the correct direction. Thus, the controller was using the wing surfaces in such a way to roll the aircraft through wing twist. To achieve the same amount of twist with a reduction in the amount of required surface motion, additional reduction in the wing structure would be required to increase torsional flexibility. In such a situation, the aircraft performance would improve since the same amount of twist would be produced with less adverse camber. 


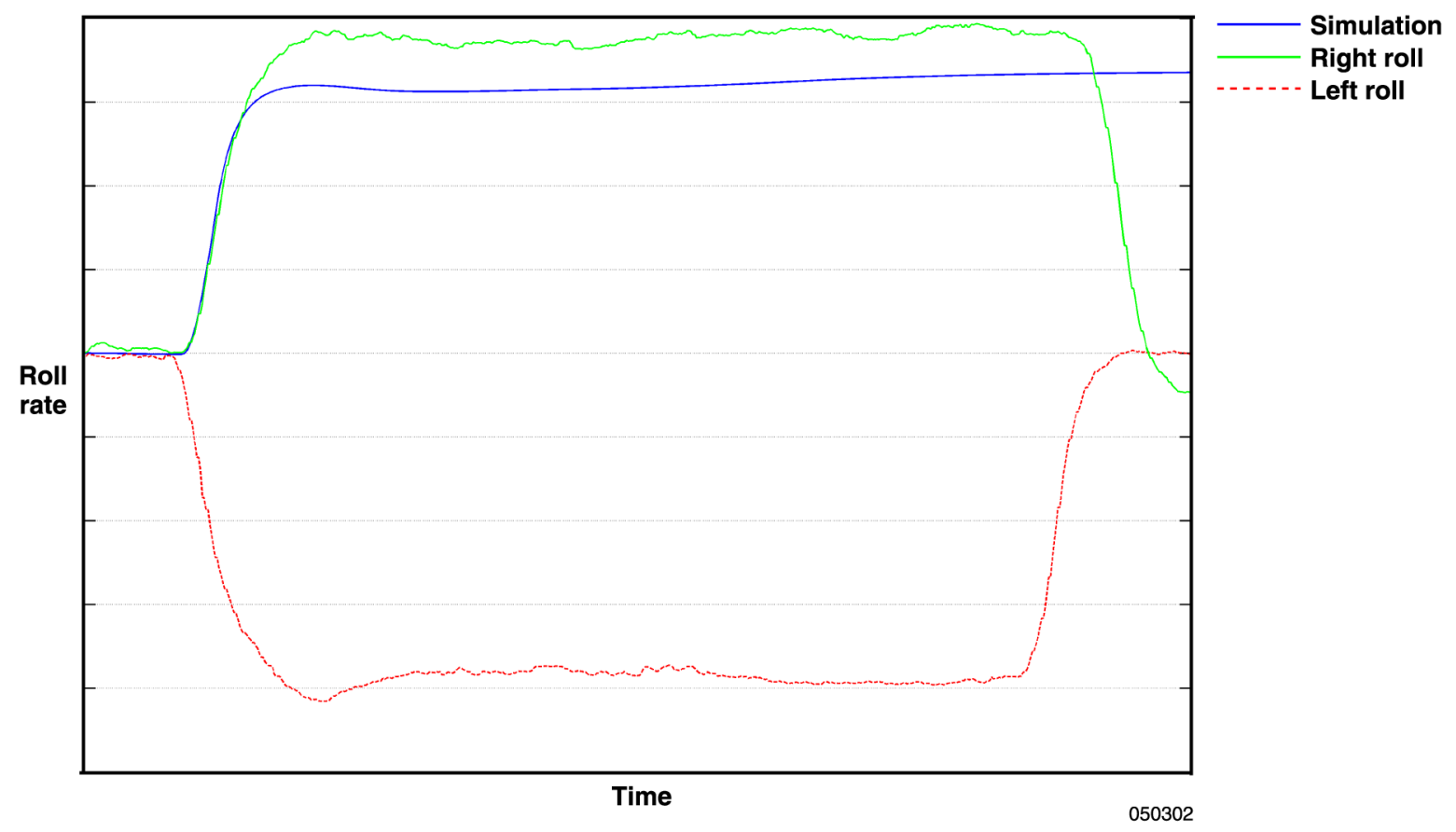

Figure 10. Roll rate: predicted left, flight left and flight right $360^{\circ}$ rolls.

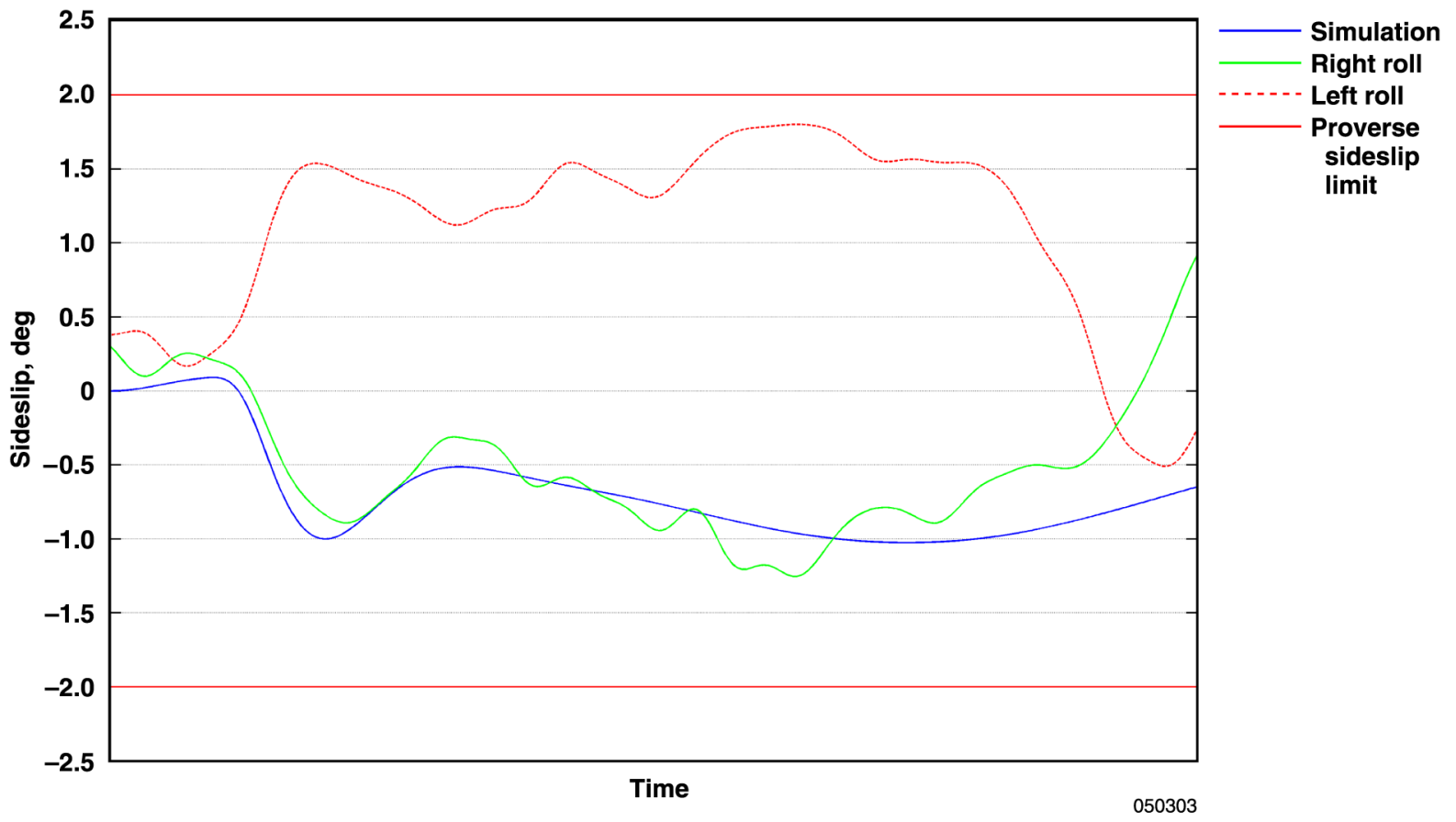

Figure 11. Sideslip: predicted left, flight left and flight right $360^{\circ}$ rolls. 

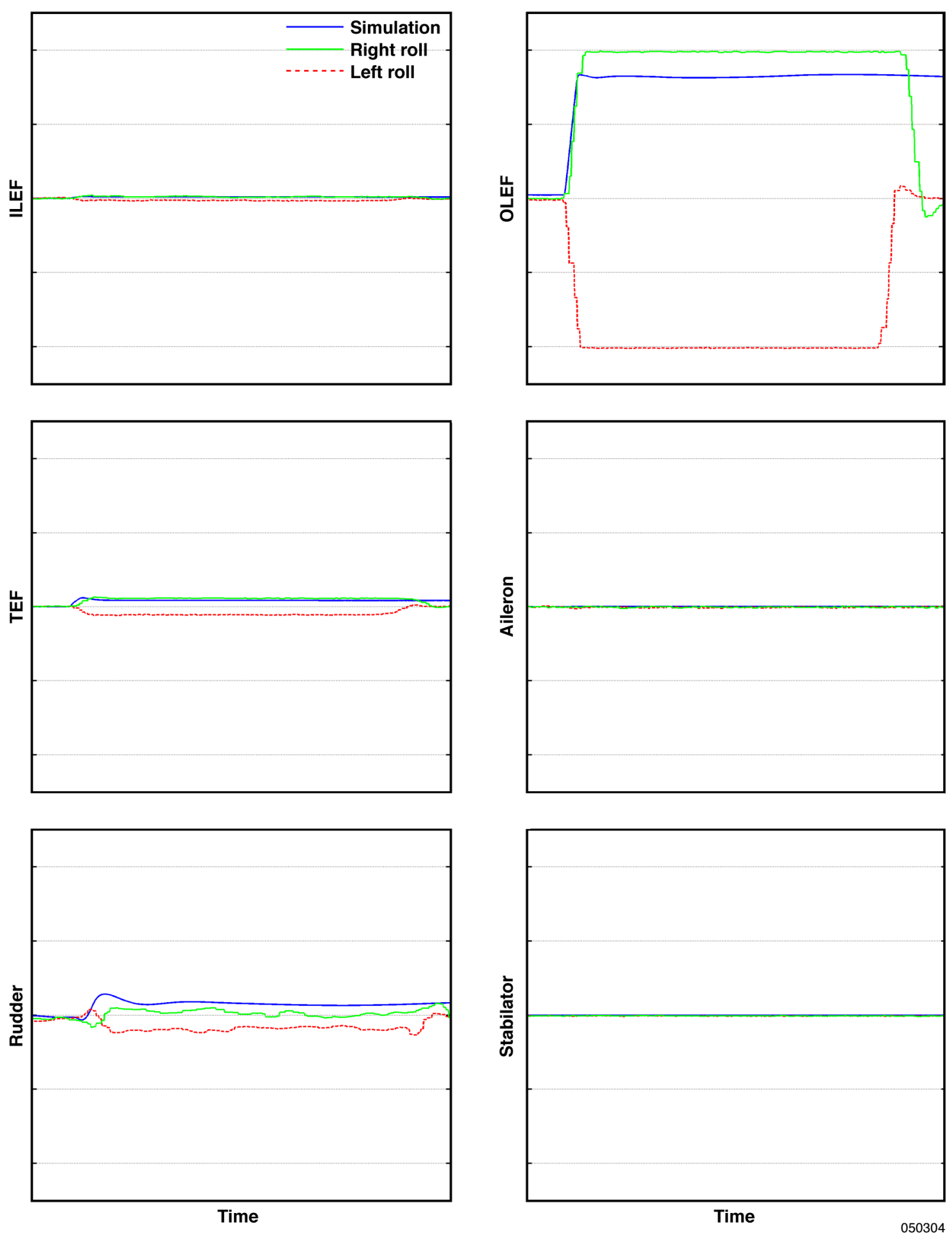

Figure 12. Surface deflections: predicted left, flight left and flight right $360^{\circ}$ rolls. 
Wing Twist (4 targets)
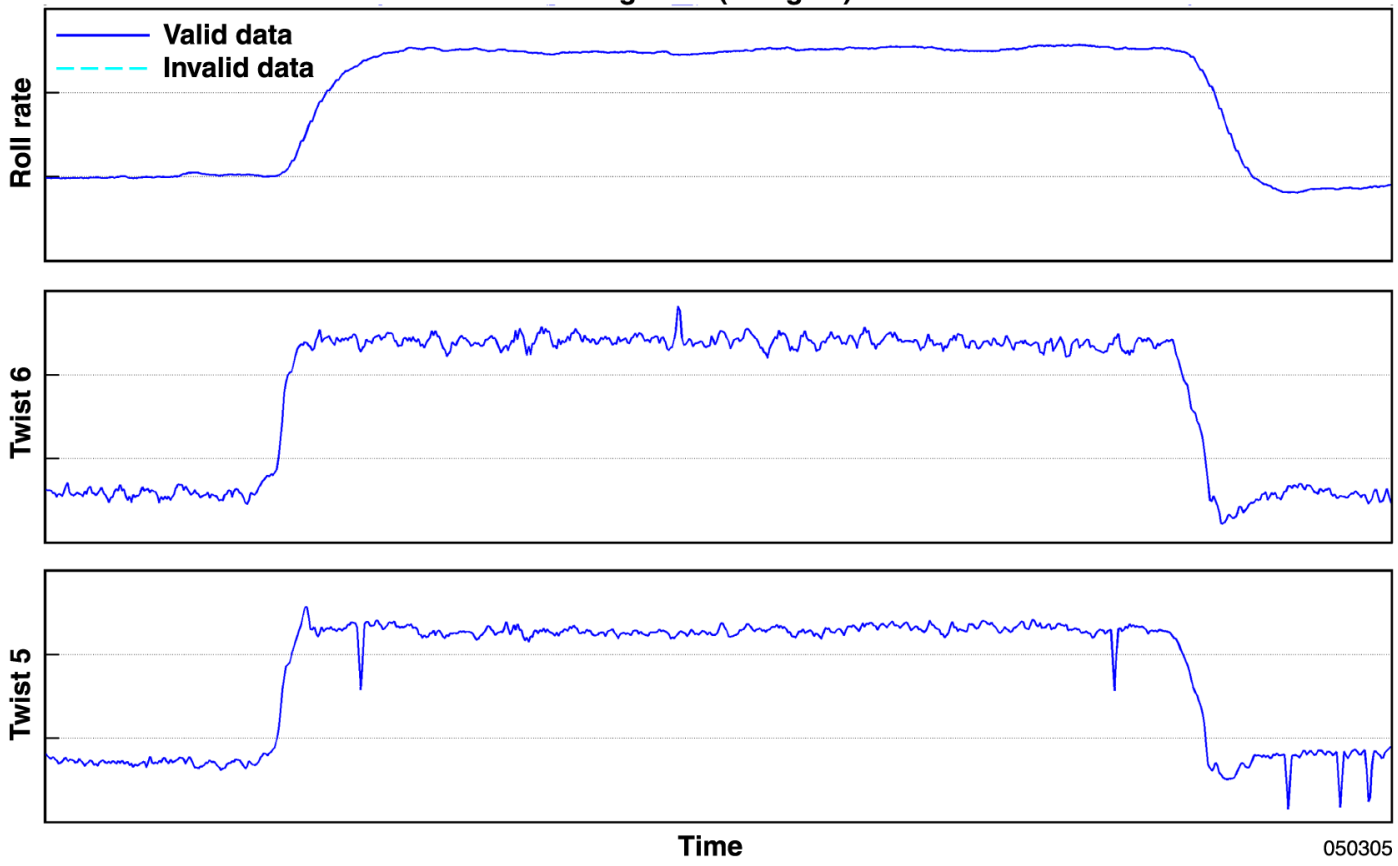

Figure 13 . Wing twist: right $360^{\circ}$ roll, positive leading edge up.
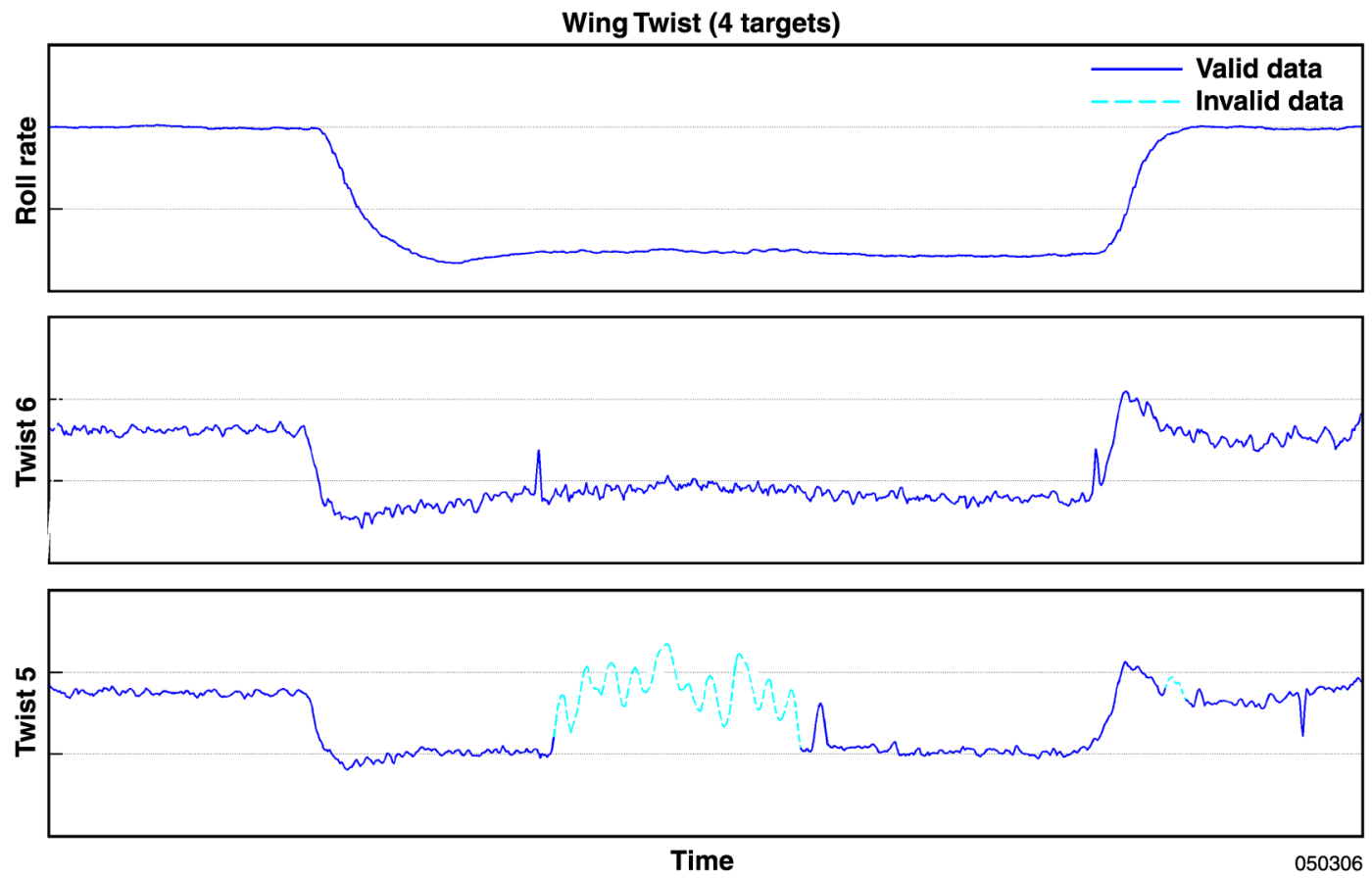

Figure 14 . Wing twist: left $360^{\circ}$ roll, positive leading edge up. 


\section{CONCLUSIONS}

A design process has been developed and proven in flight to produce control laws to roll the Active Aeroelastic Wing F/A-18 aircraft at the maximum possible roll rate, using wing twist created by using the wing control surfaces as aerodynamic tabs. Results for a representative flight condition were shown. Both loads and handling qualities requirements were maintained within acceptable levels. The roll rate for a left $360^{\circ}$ roll was greater than the same maneuver to the right due to aircraft asymmetries and both were slightly larger than the predicted simulation roll rate. Sideslip was constrained within the $2^{\circ}$ proverse limit as defined in MIL-F-8785C, matching the predicted response from simulation. Roll control was allocated almost entirely to the outboard leading-edge flaps, imparting twist on the wing to roll the aircraft. This flight condition demonstrated that effective roll control can be achieved through the use of wing twist only.

Dryden Flight Research Center

National Aeronautics and Space Administration

Edwards, California, June 29, 2005 


\section{REFERENCES}

1. Voracek, David, Ed Pendleton, Eric Reichenbach, Dr. Kenneth Griffin, and Leslie Welch, The Active Aeroelastic Wing Phase I Flight Research Through January 2003, NASA/TM-2003-210741, 2003.

2. Lokos, William A., Candida D. Olney, Natalie D. Crawford, Rick Stauf, and Eric Y. Reichenbach, Wing Torsional Stiffness Tests of the Active Aeroelastic Wing F/A-18 Airplane, NASA/TM-2002-210723, 2002.

3. Lizotte, Andrew M. and Michael J. Allen, Twist Model Development and Results From the Active Aeroelastic Wing F/A-18 Aircraft, NASA/TM-2005-212861, 2005.

4. Cumming, Stephen B. and Corey G. Diebler, "Active Aeroelastic Wing Aerodynamic Model Development and Validation for a Modified F/A-18A," AIAA-2005-6312, AIAA Atmospheric Flight Mechanics Conference and Exhibit, San Francisco, CA, August 15-18, 2005.

5. Allen, Michael J., Andrew M. Lizotte, Ryan P. Dibley, and Robert Clarke, "Loads Model Development and Analysis for the F/A-18 Active Aeroelastic Wing Airplane," AIAA-2005-6313, AIAA Atmospheric Flight Mechanics Conference and Exhibit, San Francisco, CA, August 15-18, 2005.

6. Tischler, Mark B., et al., "CONDUIT-A New Multidisciplinary Integration Environment for Flight Control Development," AIAA-1997-3773, AIAA Guidance, Navigation, and Control Conference, New Orleans, LA, 1997.

7. Cooper, George E. and Robert P. Harper, Jr., The Use of Pilot Rating in the Evaluation of Aircraft Handling Qualities, NASA TN D-5153, 1969.

8. Thornton, Stephen V., Reduction of Structural Loads Using Maneuver Load Control on the Advanced Fighter Technology Integration (AFTI)/F-111 Mission Adaptive Wing, NASA TM 4526, 1993.

9. MIL-F-8785C, "Flying Qualities of Piloted Airplanes," November 5, 1980, available from ASD/ENESS, Wright-Patterson AFB, OH.

10. MIL-STD-1797 (USAF), "Flying Qualities of Piloted Vehicles," March 31, 1987, available from ASD/ENES, Wright-Patterson AFB, OH. 
The public reporting burden for this collection of information is estimated to average 1 hour per response, including the time for reviewing instructions, searching existing data sources, gathering and maintaining the data needed, and completing and reviewing the collection of information. Send comments regarding this burden estimate or any other aspect of this collection of information, including suggestions for reducing this burden, to Department of Defense, Washington Headquarters Services,

Directorate for Information Operations and Reports (0704-0188), 1215 Jefferson Davis Highway, Suite 1204, Arlington, VA 22202-4302. Respondents should be aware that notwithstanding any other provision of law, no person shall be subject to any penalty for failing to comply with a collection of information if it does not display a currently valid $\mathrm{OMB}$ control number.

PLEASE DO NOT RETURN YOUR FORM TO THE ABOVE ADDRESS
1. REPORT DATE (DD-MM-YYYY)
28-12-2005

\section{REPORT TYPE}
Technical Memorandum
3. DATES COVERED (From - To)

\section{TITLE AND SUBTITLE}

Development and Testing of Control Laws for the Active

Aeroelastic Wing Program

5a. CONTRACT NUMBER

5b. GRANT NUMBER

5c. PROGRAM ELEMENT NUMBER

\section{AUTHOR(S)}

Ryan P. Dibley, Michael J. Allen, Robert Clarke, Joseph Gera, and John Hodgkinson

5d. PROJECT NUMBER

\section{5e. TASK NUMBER}

5f. WORK UNIT NUMBER

24-723-56-00-00-PR-SE

7. PERFORMING ORGANIZATION NAME(S) AND ADDRESS(ES)

NASA Dryden Flight Research Center

8. PERFORMING ORGANIZATION

P.O. Box 273

Edwards, California 93523-0273

H-2615

9. SPONSORING/MONITORING AGENCY NAME(S) AND ADDRESS(ES)

National Aeronautics and Space Administration

Washington, DC 20546-0001

10. SPONSORING/MONITOR'S ACRONYM(S)

NASA

11. SPONSORING/MONITORING REPORT NUMBER

NASA/TM-2005-213666

\section{DISTRIBUTION/AVAILABILITY STATEMENT}

Unclassified -- Unlimited

Subject Category 01, 05, 08 Availability: NASA CASI (301) 621-0390 Distribution: Standard

\section{SUPPLEMENTARY NOTES}

Also presented at the AIAA Atmospheric Flight Mechanics Conference and Exhibit, San Francisco, CA, August 15-18, 2005. An electronic version can be found at the NASA Dryden Flight Research Center Web site, under Technical Reports.

\section{ABSTRACT}

The Active Aeroelastic Wing research program was a joint program between the U.S. Air Force Research Laboratory and NASA established to investigate the characteristics of an aeroelastic wing and the technique of using wing twist for roll control. The flight test program employed the use of an F/A-18 aircraft modified by reducing the wing torsional stiffness and adding a custom research flight control system. The research flight control system was optimized to maximize roll rate using only wing surfaces to twist the wing while simultaneously maintaining design load limits, stability margins, and handling qualities. NASA Dryden Flight Research Center developed control laws using the software design tool called CONDUIT, which employs a multi-objective function optimization to tune selected control system design parameters. Modifications were made to the Active Aeroelastic Wing implementation in this new software design tool to incorporate the NASA Dryden Flight Research Center nonlinear F/A-18 simulation for time history analysis. This paper describes the design process, including how the control law requirements were incorporated into constraints for the optimization of this specific software design tool. Predicted performance is also compared to results from flight.

\section{SUBJECT TERMS}

AAW, Active aeroelastic wing, CONDUIT, Control reversal, F/A-18, Handling qualities, Structural loads model, Wing twist

\begin{tabular}{|c|c|c|c|c|c|}
\hline \multicolumn{3}{|c|}{ 16. SECURITY CLASSIFICATION OF: } & \multirow{3}{*}{$\begin{array}{l}\text { 17. LIMITATION OF } \\
\text { ABSTRACT } \\
\text { UU }\end{array}$} & \multirow{3}{*}{\begin{tabular}{|l} 
18. NUMBER \\
OF \\
PAGES \\
\\
28
\end{tabular}} & \multirow{2}{*}{$\begin{array}{l}\text { 19a. NAME OF RESPONSIBLE PERSON } \\
\text { STI Help Desk (email: help@sti.nasa.gov) }\end{array}$} \\
\hline a. REPORT & b. ABSTRACT & c. THIS PAGE & & & \\
\hline $\mathrm{U}$ & $\mathrm{U}$ & $\mathrm{U}$ & & & $\begin{array}{l}\text { 19b. TELEPHONE NUMBER (Include area code) } \\
\text { (301) 621-0390 }\end{array}$ \\
\hline
\end{tabular}

